\title{
A Comparative Study on the Use of Compliment Response Strategies by Persian and English Native Speakers
}

\author{
Mansour Shabani \\ English Language Department, University of Guilan, Iran \\ E-mail: mansour_shabani225@yahoo.com \\ Maryam Zeinali (Corresponding author) \\ University Campus 2, University of Guilan, Iran \\ E-mail: ailinzeinali25@gmail.com
}

Doi:10.7575/aiac.alls.v.6n.5p.58

URL: http://dx.doi.org/10.7575/aiac.alls.v.6n.5p.58
Received: 06/05/2015

Accepted: 15/07/2015

\begin{abstract}
The significance of pragmatic knowledge and politeness strategies has recently been emphasized in language learning and teaching. Most communication failures originate in the lack of pragmatic awareness which is evident among EFL learners while communicating with English native speakers. The present study aimed at investigating compliment response strategies, as a sub-category of politeness strategies, used by a group of Persian and English native speakers, and examining the effect of gender on the use of strategies to respond to compliments. To these ends and with the use of convenient sampling, thirty Iranian native speakers (15 females and 15 males) in Iran and 26 English native speakers (13 females and 13 males) in Canada, all college students with age range of 17-30, participated in this study. In order to collect a corpus of compliment responses, a researcher-made questionnaire in the form of a Discourse Completion Task was distributed among the participants. Using two-way ANOVAs, the findings indicated that there is a significant difference between Persian native speakers and Canadian English speakers $(p<.05)$ with respect to the compliment response strategies investigated in this study namely, accept, evade, and reject. Moreover, it was found that the most widely used compliment response strategy among both Iranian and English participants is accept. Regarding the effect of gender on the use of compliment response strategies by the participants, the results did not reveal a statistically significant difference between the two groups $(p>.05)$.Considering the findings of the present study, materials developers and textbook writers can make more space in EFL textbooks for exercises about compliments (responses); and help in highlighting the significance of this aspect of pragmatic knowledge.
\end{abstract}

Keywords: pragmatics, politeness, compliment, compliment response, EFL

\section{Introduction}

The significance of pragmatic knowledge has been greatly emphasized in language learning in recent years. Acquiring pragmatic competence is particularly challenging for non-native speakers. If non-native speakers transfer their pragmatic knowledge or cultural norms to the target language, it can cause misunderstanding for hearer and they cannot achieve their goal. Yule (2003, p.4) defined pragmatics as "the study of the relationships between linguistic forms and the users of those forms". In other words, pragmatics studies knowledge which enables us to understand other peoples' words and what they intend to do with the words (Cook, 2003, p. 51). Yule (2003) also believed that in order to figure out what is said in an interaction, we need to consider external and internal factors related to social distance and closeness. These factors influence not only what we say, but also how we interpret it. The investigation of this influence is normally carried out in the area of politeness theory. Green (1996; as cited in Bloomer, Griffiths, \& Merrison, 2005) claimed that politeness refers to the means which are employed to display consideration for your addressee's feelings (or face), without reference to the social distance between the addressee and the speaker. As Farashaiyan and Hua (2011) asserted, interacting with speakers of other languages and cultures needs the linguistic (grammatical) competence as well as pragmatic competence; and this is considered as one of the complexities of language learning.

Most communication failures originate in the lack of pragmatic awareness which is evident among EFL learners while communicating with people from other cultures. As pointed out by Thomas (1983), lack of pragmatic knowledge in EFL learners is partly due to the teachers who mostly concentrate on the linguistic competence and in this way they do not pay sufficient attention to the pragmatic or sociolinguistic dimensions of language. As a result, EFL learners may produce perfectly grammatical utterances; however, they may break up social norms of the target language as they lack pragmatic competence which is needed to support grammatical competence. Eslami-rasekh and Mardani (2010)noted that Iranian EFL students are not exposed to the FL community and culture; therefore, producing or even understanding a speech act is extremely difficult for them. In fact, the main reason for the pragmatic difficulties of Iranian EFL learners is that speech acts, which are considered as the dominant aspect of pragmatics, are regarded as a problematic experience for Iranian EFL learners. It is often not possible for them to produce or recognize proper patterns or strategies in the target language and they frequently transfer these patterns from their L1. Furthermore, they are often unsuccessful in identification of the appropriate function of speech acts in EFL educational contexts. 
As such, this study aims at addressing and revisiting pragmatic knowledge of Persian and English native speakers by comparing compliment responses that Iranian native speakers use in certain situations with those used by English native speakers in order to find their cross-cultural differentiation. Therefore, in the present study we seek to find the answers to the following research questions:

1. Are there any significant differences between Persian and English native speakers in terms of the use of strategies to respond to compliments?

2. Does gender have any impact on the use of strategies to respond to compliments?

To answer the research questions, the following null hypotheses are proposed:

$\mathrm{H}_{0} 1$. There are no significant differences between Persian and English native speakers in terms of the use of strategies to respond to compliments.

$\mathrm{H}_{0} 2$. Gender does not have any impact on the use of strategies to respond to compliments.

\section{Review of Literature}

Politeness is a phenomenon that has drawn researchers' attention in recent decades. It is an important area in human communication. Politeness, as an essential body in social interaction in any society, is discussed to a great extent in the field of pragmatics. Leech (1983) defined pragmatics as "the study of meaning in relation to speech situations" (p. 6).Another major concept in this regard is "face theory". Brown and Levinson (1987)explicated face theory as being composed of three basic notions including face, face threatening acts (FTAs), and politeness strategies. Brown and Levinson (1987) described FTAs as a key concern of polite behavior, and believed that in our daily life some acts inevitably run in opposition to the face needs of the speaker and/or addressee. They call these as FTAs which comprise threats, insults, and criticism. People need to make use of politeness strategy to pull through the FTA. Negative politeness strategies are utilized for addressing negative face wants, and positive politeness strategies are used for addressing positive face wants. Positive politeness includes speech acts like greeting, compliment, and invitation. Besides, negative politeness includes indirectness and apologies. A speech act, which is one of the major areas within the realm of pragmatics, is the smallest unit in human communication used to perform acts such as requesting, apologizing, complimenting, and thanking. Austin (1962) defined speech acts as the actions performed in saying something. Speech acts function by means of universal principles of pragmatics (e.g., Austin 1962; Searle 1979), or of politeness (e.g., Brown and Levinson 1978, 1987; Leech 1983). As noted above, compliments are one type of speech acts which are subsumed under the category of positive politeness. Holmes (1986), indicated that compliment is "a speech act which explicitly or implicitly attributes credit to someone other than the speaker, usually the person addressed, for some 'good' (possession, characteristic, skill, etc.), which is "positively valued by the speaker and the hearer" (Holmes, 1988, p. 486). Compliment responses are also being extensively studied since they can be used to perform different functions. Using an appropriate compliment and compliment response can result in a successful communication. It is of paramount importance to note that giving a compliment or responding to it without any knowledge of the culture and its compliment norms can be very threatening (Holmes, 1988).

In recent years, many studies have been conducted to describe various aspects of speech acts across languages and most of them have compared speech-act behaviors in Western and non-Western cultures. Holmes (1986) conducted a comprehensive study on complimenting behavior. Using a corpus of 500 compliments responses generated by speakers of New Zealand English, she analyzed the lexical and syntactic patterns of compliments and the functional categories of compliment responses. As Zhang (2013) mentioned, Holmes' (1986) ethnographic research found that in the corpus six adjectives were used with high frequency and accounted for about two thirds of all the adjectives used. However, the occurrence of the distinctively New Zealand syntactic variants was also noted in the obtained results. Holmes also conducted other studies in the years 1988 and 1993. Based on her findings, she proposed taxonomy of CR strategies which comprise of three macro level CRs, namely Accept, Reject and Deflect/Evade illustrated in Table 2.1 below. Holmes (1986) found that the most common response to a compliment was to accept it (61.1\%), and the next frequent response was to deflect/evade a compliment (28.8\%). It was also indicated that New Zealand English speakers rarely rejected a compliment $(10 \%)$.

Table 2.1 Holmes' $(1988,1993)$ taxonomy of CR strategies

\begin{tabular}{|c|c|c|}
\hline Macro level CRs & Micro level Crs & Examples \\
\hline \multirow[t]{6}{*}{ Accept } & Appreciation token & "Thank you"; "Cheers", "Yes" \\
\hline & Agreeing utterance & "Yes, I really like it"; "I know" \\
\hline & Downgrading & "It's nothing" \\
\hline & Utterance & "I enjoyed doing it" \\
\hline & Return compliment & "It's not bad" \\
\hline & & "You've got beautiful too" \\
\hline \multirow[t]{3}{*}{ Reject } & Disagreeing utterance & "No, it was good". \\
\hline & Question accuracy & "Really?" \\
\hline & Challenge sincerity & "Don’t lie"; "Come on" \\
\hline \multirow[t]{3}{*}{ Evade } & Shift credit & $\begin{array}{l}\text { "you're polite"; "That's what } \\
\text { friends are for" }\end{array}$ \\
\hline & Informative comment & "It was not hard" \\
\hline & Request reassurance & "Really?" \\
\hline
\end{tabular}


Although different language speakers use diverse verbal and nonverbal behaviors in their communication, this may cause misunderstanding and difficulty for them when two speakers from different cultures want to interact with each other. In Asian cultures, "the words are the part of communication, that includes the characters of the parties involved and the nature of the interpersonal relationships between them" (Gudykunst \& Kim, 2003, p.216).However, in western cultures verbal message is important. Persian speakers are persistent to "make use of any compliments or praise that they receive to enhance the aberu of their interlocutors, their family, or whoever might have directly or indirectly contributed to a success or achievement" (Sharifian \& Palmer, 2007, p. 42). Persian speakers use many expressions to show their modesty. Also, cultural differences can cause embarrassment. As exemplified by Tang and Zhang, "while 'you look lovely today' may make an English woman's day, it may well make a Chinese woman uncomfortable and even somewhat resentful” (2009, p. 326).

In what follows a number of studies on Persian compliments and compliment responses will be reviewed. Akbari (2002) comparatively investigated the principles of politeness in Persian and English based on the model proposed by Brown and Levinson (1987). She found that there was no in-built incongruity between the existences of universal properties and the effects of linguistic and cultural differences on the linguistic construction of utterances. However, she claimed that, when cultural difference in interpretive strategies is carried over from one language to another, misunderstandings may happen and it may also lead to stereotyping of interactional styles across-group. In a study by Sharifian (2005), it was attempted to illuminate the Persian cultural schema of modesty, i.e., shekasteh-nafsi, and how the schema may be embodied in Persian speakers' replies to compliments. To this aim, a DCT was utilized to collect Persian and English language data from two groups of Iranian and Australian participants. The results revealed that Persian speakers were greatly influenced by the cultural schema of shekasteh-nafsi in their responses to compliments. Data gained from the English speakers did not show a similar schema; however, it was shown that a certain degree of overlap exists in Australian English speakers 'responses with the Persian speakers in terms of downplaying the trait which was the goal of the compliment. Karimnia and Afghari (2011) have also investigated the notion of compliments in English and Persian interactions cross-culturally. Using Brown and Levinson's (1987) model, results of their study revealed that Persian and English speakers use different strategies. Moreover, they found that culture has a significant effect on the speakers' speech act performance.

\section{Methodology}

\subsection{Participants}

Thirty Iranian native speakers (15 females and 15 males) in Iran and 26 English native speakers (13 females and 13 males) in Canada participated in this study. The age of the participants varied from 17- 30 and they were all college students. All the English respondents were Canadian native speakers of English and no one was an immigrant from other countries. Also, the participants were selected from different educational backgrounds (below B.A., B.A., and M.A.) and were asked to note down how they may reply to the compliments. Since it was not possible to make a random selection, the selection of the participants was based on convenient sampling.

\subsection{Instruments}

In the present study we made use of a researcher-made questionnaire in the form of a Discourse Completion Task (DCT) (available in the Appendix). The main advantage of using a DCT as the most commonly-used data collection tool in pragmatics (Talleraas, 2014), is that it enables the researchers to collect large amounts of data in a short amount of time. The DCT was prepared using previous research such as the studies conducted by Enssaif (2005), MotaghiTabari and de Beuzeville (2012), and Talleraas (2014). In it a number of situations were described and the participants were asked to write their responses in the blank spaces following the described situations. It consisted of two parts. The first section contained questions regarding the demographic information of the participants such as their gender, and level of education. In the second section, the respondents were presented with twenty situations which aimed at eliciting the kinds of compliment responses they utilize. In fact, the participants were asked to write their responses in English or Persian as if they were responding verbally in real situations. It needs to be noted that the same questionnaire was translated for Persian speakers. It should be mentioned that the DCT was thoroughly analyzed by two experienced university professors. One of them was an expert in Applied Linguistics. The other professor was also knowledgeable in the stylistic aspects.

\subsection{Data collection procedures}

In order to collect a corpus of compliment responses which were the requirements of the present study, the participants were asked to answer the questionnaire with no time limit being set, and they were given enough time to return the questionnaire. For the participants in Iran, the questionnaires were distributed by the researcher and due explanations were made on the spot. Regarding the Canadian participants, some of the questionnaires were handed to the participants by a friend, and some were sent via e-mails. In all the cases, it was tried to make the objectives of the questionnaire clear to those who agreed to complete the questionnaire, and they were also informed of the confidentiality of their responses. Total time for data collection, both in Iran and in Canada was about 3 months.

\subsection{Data analysis}

For data analysis, two university professors were asked to randomly check the responses given by the participants. Then, in order to answer research questions, the participants' responses to each item of the questionnaire were coded and analyzed based on Holmes' $(1988,1993)$ studies on complimenting behavior. Descriptive statistics including mean, 
frequency, and percentages were also utilized. In addition, two-way ANOVAs were run on the data to examine the statistical significance of the results obtained

\section{Results and discussion}

Table 4.1 demonstrates descriptive statistics regarding male and female Persian native speakers' use of the compliment response strategies investigated in the present study. It presents the frequency, mean and percentage of the use of each strategy.

Table 4.1 Desciptive statistics for male and female Persian native speakers' use of compliment response strategies

\begin{tabular}{ccccccc}
\hline & \multicolumn{2}{c}{ Strategies } & \multicolumn{2}{c}{ reject } \\
\cline { 2 - 7 } & \multicolumn{2}{c}{ accept } & \multicolumn{2}{c}{ evade } & male & female \\
& male & female & male & Female & f & f \\
1 & $\mathbf{f}$ & $\mathbf{f}$ & $\mathbf{f}$ & $\mathbf{F}$ & 3 & 2 \\
2 & 14 & 14 & 3 & 4 & 0 & 1 \\
3 & 19 & 17 & 1 & 2 & 0 & 0 \\
4 & 17 & 17 & 3 & 3 & 0 & 0 \\
5 & 20 & 18 & 0 & 2 & 2 & 1 \\
6 & 17 & 15 & 1 & 4 & 2 & 1 \\
7 & 16 & 15 & 2 & 4 & 1 & 1 \\
8 & 17 & 14 & 2 & 5 & 1 & 0 \\
9 & 15 & 16 & 4 & 4 & 0 & 2 \\
10 & 17 & 16 & 3 & 2 & 0 & 0 \\
11 & 16 & 17 & 4 & 3 & 2 & 1 \\
12 & 10 & 15 & 8 & 4 & 3 & 1 \\
13 & 15 & 12 & 2 & 7 & 2 & 2 \\
14 & 12 & 13 & 6 & 5 & 1 & 2 \\
15 & 13 & 12 & 6 & 6 & 2 & 1 \\
Total & 16 & 15 & 2 & 4 & 19 & 15 \\
Mean & 234 & 226 & 47 & 59 & 1.26 & 1 \\
Percentage & 15.60 & 15.06 & 3.13 & 3.94 & $5.33 \%$ & $\mathbf{5 \%}$ \\
\hline & $\mathbf{7 8 \%}$ & $75.33 \%$ & $15.66 \%$ & $19.66 \%$ & $6.3 \%$ \\
\hline
\end{tabular}

As the table shows, the most widely used strategy among Persian native speakers who participated in this study is accept $(78 \%)$, and it is mostly used by males. On the other hand, reject is the least widely used compliment response strategy (5\%), which is used among females.

Table 4.2 presents descriptive statistics for the use of compliment response strategies among male and female English native speakers. It includes the frequency, mean, and percentage of the use of the strategies.

Table 4.2 Desciptive statistics for male and female English native speakers' use of compliment response strategies

\begin{tabular}{|c|c|c|c|c|c|c|}
\hline \multirow{4}{*}{ No. } & \multicolumn{6}{|c|}{ Strategies } \\
\hline & \multicolumn{2}{|c|}{ accept } & \multicolumn{2}{|c|}{ Evade } & \multicolumn{2}{|c|}{ reject } \\
\hline & Male & female & male & female & male & female \\
\hline & $\mathbf{f}$ & f & f & F & f & f \\
\hline 1 & 13 & 15 & 3 & 5 & 4 & 0 \\
\hline 2 & 18 & 18 & 2 & 2 & 0 & 0 \\
\hline 3 & 17 & 1 & 1 & 5 & 2 & 1 \\
\hline 4 & 19 & 15 & 0 & 2 & 1 & 3 \\
\hline 5 & 1 & 18 & 1 & 2 & 2 & 0 \\
\hline 6 & 19 & 17 & 0 & 3 & 1 & 0 \\
\hline 7 & 20 & 19 & 0 & 0 & 0 & 1 \\
\hline 8 & 19 & 16 & 0 & 1 & 1 & 3 \\
\hline 9 & 18 & 19 & 2 & 1 & 0 & 0 \\
\hline 10 & 19 & 19 & 1 & 0 & 0 & 1 \\
\hline 11 & 14 & 20 & 5 & 0 & 1 & 0 \\
\hline 12 & 1 & 18 & 1 & 2 & 0 & 0 \\
\hline 13 & 18 & 15 & 2 & 5 & 0 & 0 \\
\hline Total & 230 & 223 & 18 & 28 & 12 & 9 \\
\hline Mean & 17.69 & 17.15 & 1.38 & 2.15 & 1 & 69 \\
\hline Percentage & $88.64 \%$ & $74.3 \%$ & $6.92 \%$ & $9.33 \%$ & $4.61 \%$ & $3 \%$ \\
\hline
\end{tabular}


It can be seen in the table that, as for the Persian native speakers, accept is the most widely used strategy (88.64\%), and it is mostly used by males. Moreover, the least widely used compliment response strategy is found to be reject (3\%), used by female English native speakers.

Table 4.3 demonstrates the results of two-way ANOVA ran on the data to find whether there are statistically significant differences between Persian and English native speakers in terms of the use of strategies (accept, reject, or evade) to respond to compliments.

Table 4.3 Results of two-way ANOVA for the use of compliment response strategies

\begin{tabular}{|c|c|c|c|c|c|}
\hline \multicolumn{6}{|c|}{ Dependent Variable: number } \\
\hline Source & $\begin{array}{l}\text { Type III } \\
\text { Sum of } \\
\text { Squares }\end{array}$ & df & $\begin{array}{l}\text { Mean } \\
\text { Square }\end{array}$ & $\mathbf{F}$ & Sig. \\
\hline Corrected Model & $7990.733^{a}$ & 5 & 1598.147 & 552.49 & .000 \\
\hline Intercept & 7428.571 & 1 & 7428.571 & 2568.1 & .000 \\
\hline Strategy & 7960.650 & 2 & 3980.325 & 1376.0 & .000 \\
\hline language & .000 & 1 & .000 & .000 & 1.000 \\
\hline $\begin{array}{l}\text { Strategy * } \\
\text { language }\end{array}$ & 105.650 & 2 & 52.825 & 18.26 & .000 \\
\hline Error & 468.600 & 162 & 2.893 & & \\
\hline Total & 15926.000 & 168 & & & \\
\hline Corrected Total & 8459.333 & 167 & & & \\
\hline
\end{tabular}

a. R Squared $=.945$ (Adjusted R Squared $=.943)$

As indicated in the table, the results of a two-way ANOVA showed that the main effect of strategy is significant $(F$ $(2,162)=1376.0, p=.00)$, as the $p$-value is less than our assumed alpha level $(P<.05)$. However, the effect of language is non-significant $(F(1,162)=.00, p=1.00)$. Nevertheless, the interaction effect is shown to be significant $(F(2,162)=$ $18.26, p=.00)$.

As a significant difference was found in the interaction between the use of language and compliment response strategies, the post-hoc Tukey HSD test was conducted, and its results are presented in the following table:

Table 4.4 Results of Tukey's post-hoc test for comparison among the compliment response strategies

Dependent Variable: number

Tukey HSD

\begin{tabular}{|c|c|c|c|c|c|c|}
\hline \multirow{2}{*}{$\begin{array}{l}\text { (I) } \\
\text { trategy }\end{array}$} & \multirow{2}{*}{$\begin{array}{c}(\mathrm{J}) \\
\text { Strategy }\end{array}$} & \multirow{2}{*}{$\begin{array}{c}\text { Mean } \\
\text { Difference } \\
\text { (I-J) }\end{array}$} & \multirow{2}{*}{$\begin{array}{l}\text { Std. } \\
\text { Error }\end{array}$} & \multirow[t]{2}{*}{ Sig. } & \multicolumn{2}{|c|}{$95 \%$ Confidence Interval } \\
\hline & & & & & $\begin{array}{l}\text { Lower } \\
\text { Bound }\end{array}$ & $\begin{array}{l}\text { Upper } \\
\text { Bound }\end{array}$ \\
\hline \multirow[t]{2}{*}{ accept } & evade & $13.5893^{*}$ & .32141 & .000 & 12.8290 & 14.3496 \\
\hline & reject & $15.3214^{*}$ & .32141 & .000 & 14.5611 & 16.0817 \\
\hline \multirow[t]{2}{*}{ evade } & accept & $-13.5893^{*}$ & .32141 & .000 & -14.3496 & -12.8290 \\
\hline & reject & $1.7321^{*}$ & .32141 & .000 & .9719 & 2.4924 \\
\hline \multirow[t]{2}{*}{ reject } & accept & $-15.3214^{*}$ & .32141 & .000 & -16.0817 & -14.5611 \\
\hline & evade & $-1.7321^{*}$ & .32141 & .000 & -2.4924 & -.9719 \\
\hline
\end{tabular}

*. The mean difference is significant at the 0.05 level.

Table 4.4 indicates that the differences among all the three compliment response strategies including accept, reject, and evade are statistically significant $(p<.05)$.

Table 4.5 presents the results of another two-way ANOVA ran in order to find the probable impact of gender on the use of compliment response strategies by both male and female participant of the study. 
Table 4.5 Results of two-way ANOVA for the effect of gender on the use of compliment response strategies

\begin{tabular}{|c|c|c|c|c|c|}
\hline \multicolumn{6}{|c|}{ Dependent Variable: number } \\
\hline Source & $\begin{array}{l}\text { Type III } \\
\text { Sum of } \\
\text { Squares }\end{array}$ & df & $\begin{array}{l}\text { Mean } \\
\text { Square }\end{array}$ & $\mathbf{F}$ & Sig. \\
\hline Corrected Model & $7898.619^{a}$ & 5 & 1579.724 & 456.40 & .000 \\
\hline Intercept & 7466.667 & 1 & 7466.667 & 2157.2 & .000 \\
\hline Strategy & 7885.083 & 2 & 3942.542 & 1139.0 & .000 \\
\hline gender & .000 & 1 & .000 & .000 & 1.000 \\
\hline $\begin{array}{c}\text { Strategy } \\
\text { gender }\end{array}$ & 13.536 & 2 & 6.768 & 1.955 & .145 \\
\hline Error & 560.714 & 162 & 3.461 & & \\
\hline Total & 15926.000 & 168 & & & \\
\hline Corrected Total & 8459.333 & 167 & & & \\
\hline
\end{tabular}

a. $\mathrm{R}$ Squared $=.934$ (Adjusted R Squared $=.932)$

As demonstrated in the table, at the alpha level of .05 , there is a main effect for the use of compliment response strategies $(F(2,162)=1139.06, p=.00)$. However, there is not a statistically significant effect for gender $(F(1,162)=$ $.00, p=1.00$ ). In fact, gender does not have an effect in the use of strategies among the participants of the present study. The interaction effect is also non-significant $(F(2,162)=1.00, p=.14)$.

The present study aimed at investigating compliment response strategies used by a group of Persian native speakers living in Iran and English native speakers living in Canada. It also sought to examine whether gender has any statistically significant impact on the use of strategies to respond compliments. In order to fulfill the aim of the study, we made use of a validated questionnaire in form of a DCT which was prepared in both Persian and English versions.

The results obtained in the present study showed that as a whole there is a significant difference between Persian speakers and Canadian English speakers in terms of their use of compliment response strategies. In fact, the results of two-way ANOVA made it clear that at the significance level of .05 and concerning the compliment response strategies investigated in this study namely, accept, evade, and reject there is not a similarity between Persian native speakers and Canadian English speakers $(p<.05)$.However, considering the frequency and order of using the three investigated compliment response strategies, the findings of the present study revealed that there is similarity between the two groups. To put it more specifically, based on the results it was shown that the most widely used compliment response strategy among both Iranian and English participants is accept. Also, considering both Persian and Canadian English speakers, the two other strategies including evade and reject are in the second and third order of usage. Therefore, based on the findings, we are partly safe to reject the first null hypothesis of this study, that is, there are no significant differences between Persian and English native speakers in terms of the use of strategies to respond to compliments. These findingsare in line with the results of the studies of Holmes $(1986,1988)$ in which it was revealed that the most frequent response to compliments by people in New Zealand is accept. This finding also lends support to the study of Razi (2013) who made a comparison between Australian and Iranian people in terms of their use of compliment response strategies. Razi (2013) also found that among the three compliment response strategies accept is in the first place of usage followed by evade and reject. Razi (2013) also mentioned that there is no universal model in the use of compliment responses and people from different cultures use a variety of compliments responses. In the present study we found that there is a similarity between Iranian culture and Canadian English culture in responding to compliments, as accepting the compliments is common in both cultures. Moreover, what was found in the present study supports the findings of Sadeghi and Zarei (2013) who emphasized the cultural similarity between Persian and English speakers in terms of their preference for using the compliment response of accept. However, these findings are in contrast to what Sorahi and Nazemi (2013) mentioned about the use of compliment response strategies by Iranian Persian speakers and their Australian counterparts. They found that Iranian Persian speakers make fewer use of accept strategies and they mostly use reject and evade strategies when responding to the compliments addressed to them, which is different from Australian English speakers who mostly use the accept strategy in these situations.

Concerning the effect of gender on the use of compliment response strategies by Persian native speakers and Canadian English speakers the findings of the present study did not reveal a statistically significant difference between the two groups $(p>.05)$. Accordingly, the second null hypothesis of this study, that is, gender does not have any impact on the use of strategies to respond to compliments cannot be rejected. This finding is in contrast with what Holmes (1986) found with regard to the effect of gender on the use of compliment response strategies. Holmes' study in 1986 revealed that male and female's preference for using compliment response strategies is not similar, and females tend to accept compliments more than males. Furthermore, the results of the present study concerning gender differences in using compliment response strategies do not support the findings of Cai (2012) who argued that there is a difference between males and females in responding to compliments. In fact, Cai's (2012) findings revealed that the female participants 
preferred to use explicit acceptance more than males. However, in the present study, we did not witness a significant difference between males and females in this regard.

\section{Conclusion}

On the basis of the findings of the present study it was revealed that generally, Persian and English native speakers use different strategies to respond to compliments. In fact, results of two-way ANOVA showed a statistically significant difference between the two groups $(p<.05)$. However, the results also indicated that both Persian and English participants of the present study tend to accept compliments addressed to them. Considering the second research question, the findings revealed that the variable of gender does not make any difference in the use of compliment response strategies. In other words, results of another two-way ANOVA ran on the data did not show any statistically significant difference between males and females who took part in the present study $(p>.05)$.

With regard to what was found in the present study, pedagogical implications for EFL practitioners can be delineated. Considering EFL teachers or instructors, it can be claimed that by raising EFL learners' awareness of the pragmatic features of Persian and English languages, teachers can prepare the ground to avoid misunderstanding and serious breakdowns in communication. In fact, making the learners aware of the similarities and differences between or among people of different cultures is a significant part of any language learning situation. Moreover, as mentioned by $\mathrm{Al}$ Falasi (2007) it is incumbent upon syllabus designers to consider learners' needs in comprehension and production of speech acts. As such, with regard to what was found in the present study about the difference between Persian native speakers and Canadian English speakers in responding to compliments, materials developers can make more space in EFL textbooks for providing more exercises about this aspect of pragmatic knowledge, and help in consolidation of this knowledge. Additionally, as it was found that there are some similarities between Persian and English speakers in terms of using the compliment response strategies of accept, evade and reject; and since this is in line with the previous literature, textbook writers can highlight this fact by drawing the attention of practitioners toward it.

The present study is limited in a number of ways. First and foremost, due to insufficient sample size and non-random selection of the participants the results of this study cannot be extended to the entire population of Persian and English native speakers. Also, in this study we could not gather naturally occurring data in casual settings, as we did not have access to the participants living abroad. We had tried to delimit the results obtained from this research by controlling for the gender effect and considering some important situations for using compliments and compliment response strategies. As such, in order to be able to handle the wide range of participants' responses in the vast area of pragmatic meaning we included some aspects of this area. In spite of these issues, the present study could be said to have achieved success in eliciting the kind of compliment response strategies more commonly used by a group of Persian and English native speakers with special attention to gender effect.

As the present study was a small-scale research with a limited number of participants, further research is needed which can replicate this study using a larger population. Furthermore, since the data collection tool utilized in the present study was a questionnaire in form of a DCT, which contained some specific situations, further studies is needed that address more pragmatic situations. Also, the findings can be strengthened if interviews could be conducted to elicit more genuine data.

\section{References}

Akbari, Z. (2002). The realization of politeness principles in Persian. Karen Linguistics Issues 12, 120-135.

Al Falasi, H. (2007). Just say thank you: A study of compliment responses. The Linguistics Journal, 2 (1), 28-42.

Austin, J. (1962). How to do things with words. Oxford: Oxford University Press.

Bloomer, A., Griffiths, P., \& Merrison, A.J. (2005). Introducing language in use: A course book. Oxon: Routledge.

Brown, P., \& Levinson, S. (1978). Universals in language usage: Politeness phenomena. In E. Goody (Ed.), Questions and politeness (pp. 56-311). Cambridge: Cambridge University Press.

Brown, P., \& Levinson, S. (1987). Politeness: Some universals in language usage. Cambridge: Cambridge University Press.

Cai, Y. (2012). A study on compliment response strategies by Chinese college students. Journal of Language Teaching and Research, 3(3), 543-549.

Cook, G. (2003). Applied linguistics. Oxford: Oxford University Press.

Enssaif, Z. A. (2005). Compliment behavior: Strategies and realizations in English and Arabic: A case study of female students of the English department, King Saud University. (Unpublished master's thesis). King Saud University, Riyadh- KSA.

Eslami-Rasekh, A., \& Mardani, M. (2010).Investigating the effects of teaching apology speech act, with a focus on intensifying strategies, on pragmatic development of EFL learners: The Iranian context. The International Journal of Language, Society and Culture, 30, 96-103.

Farashaiyan, A ., \& Hua, T. (2011).On the relationship between pragmatic knowledge and language proficiency among Iranian male and female undergraduate EFL learners. The Southeast Asian Journal of English Language Studies, 18 (1), 33-46.

Gudykunst, W., \& Kim, Y.Y. (2003).Communicating with strangers: An approach to intercultural communication. NewYork: McGraw-Hill. 
Herbert, R. (1990). Sex-based differences in compliment behavior. Language in Society 19, 201-224.

Holmes, J., (1986). Compliments and compliment responses in New Zealand English. Anthropological Linguistics, 28(4), 485-508.

Holmes, J. (1993). New Zealand women are good to talk to: An analysis of politeness strategies in interaction. Journal of Pragmatics, 20(2), 91-116.

Holmes, J. (1988). Paying compliments: A sex preferential positive politeness strategy. Journal of Pragmatics, 12(3), 445-465.

House, J. \& Kasper, G. (1981). Politeness markers in English and German. In F. Coulmas (Ed.). Conversational routine. The Hague: Mouton.

Karimnia, A. \& Afghari, A. (2011). Compliments in English and Persian interaction: A cross-cultural perspective. Jezikoslovlje, 12(1), 27-50.

Leech, G. N. (1983). Principles of pragmatics. London: Longman.

Lorenzo-Dus, N. (2001). Compliment responses among British and Spanish university students: A contrastive study. Journal of Pragmatics, 33, 107-127.

Motaghi-Tabari, Sh., de Beuzeville, L. (2012). A contrastive study of compliment responses among Persians and Australians: The effects of exposure to a new speech community. Applied Research in English, 1(1), 21-42.

Razi, N. (2013). A contrastive study of compliment responses among Australian English and Iranian Persian speakers. Procedia - Social and Behavioral Sciences, 70, 61-66.

Sadeghi, E., \& Zarei, G. R. (2013).Investigating the use of compliments in Persian and English: A case study of Iranian EFL students. Journal of Foreign Language Teaching and Translation Studies, 2(2), 30-49.

Sharifian, F. (2005). The Persian cultural schema of shekasteh-nafsi: A study of compliment responses in Persian and Anglo-Australian speakers. Pragmatics \& Cognition, 13(2), 337-361.

Sharifian, F. (2011).Cultural conceptualizations and language: theoretical framework and applications. Amsterdam: John Benjamins Publishing Co.

Sharifian, F., \& Palmer, G. (2007).Applied cultural linguistics: An emerging paradigm. In F. Sharifian \& G. Palmer (Eds.), Applied cultural linguistics: implications for second language learning and intercultural communication (pp. 114). Amsterdam: John Benjamins Publishing Co.

Sorahi, M. A., \& Nazemi, T. B. (2013). A cross-cultural study of the use of compliment strategies among English and Persian speakers. Middle-East Journal of Scientific Research, 16(9), 1292-1296.

Talleraas, T. (2014).Compliments on your competence: A comparative study on compliment responses from Norwegian English foreign language learners and native speakers of English with a focus on pragmatic competence and idiomatic expressions. (Unpublished master's thesis). Universitetet I Oslo.

Thomas, J. (1983). Cross-cultural pragmatic failure. Applied Linguistics, 4, 91-112.

Tang, C. H., \& Zhang, G.Q. (2009). A contrastive study of compliment responses among Australian English and Mandarin Chinese speakers. Journal of Pragmatics, 41(2), 325-345.

Yule, G. (2003). Pragmatics. Oxford: Oxford University Press.

Zhang, J. P. (2013). Compliments and compliment responses in Philippine English. Journal of Language Studies, $13(1)$.

\section{Appendix A}

The English Questionnaire Used in the Present Study

\section{Demographic information}

Gender male $\square$ female $\square$

\section{Level of Education Below BA o BAo Above BAo}

Age:

Please write what you would say in response to the utterances in the following situations.

1. How would you respond to your uncle in the following situation? You have taken part in a party and you have faced some of your relatives that you have not met for years. Suddenly, your uncle finds you among people and asks you "introduce your daughter to him" then your uncle says," You have such a lovely daughter."

You will say:

2. You pay attention a lot to your health; you try to get all of vitamins naturally and always eat fruit for desserts instead of cookies. Your friend always admires your eating habits and says:" I like to follow your diet". How would you respond to him? 
3. How would you respond to your friend in the following situation? One of your friends decides to start a business; he asks you to help him as a manager and give him some advice. When you share your experience with him, he says, "Thank you, Jack. It is an honor to have you in our program. You are really smart".

You will say:

4. You area nutritionist and always encourage your preschooler to help you prepare meals and snacks. By this you want to teach your child to tear lettuce or add veggie toppings to her pizza. Your husband says" I'm proud of you, you change our way of eating". How would you respond to him?

5. How would you respond in the following situation? One of your friends is moving to a new house and you have helped your friends (a couple) to look after their child for a whole day at your place. When they come back to pick up the child, they say "you are our nice friend that we can always count on you".

6. How would you respond in the following situation? Your friend has organized a big party to celebrate the end of the semester. She has invited most of her classmates. You've dressed up for the party and tried to look different. As you arrive at the party, one of your friends says you look appealing tonight

7. How would you respond in the following situation? You are in the first seminar of a new term. You sit next to a student that you haven't spoken to before. He says, "I like your bag." You will say:

8. How would you respond in the following situation? You have been invited to a seminar and you should give a presentation. You worked a lot on your presentation and you are completely ready. When you finish your presentation, most of people clap you and one of your colleagues says, "That was a great presentation!" You will say:

9. You always eat low-fat versions of milk, cheese, yogurt, and other milk products. Because your doctor warns you for cholesterol, so you try to be careful of your eating habit because of this your close friend always appreciates your will and says it is extraordinary that you care of your health. How would you respond to your friend?

10. You and your friend are talking about your memories you tell him "I was driving on a snowy road during charismas suddenly I got stuck in snow, and then I used my mechanic talent to get off the hook. Your friend says "wow. You are so intelligent in mechanic; you survived due to your talent".

You will say:

11. How would you respond in the following situation? You and a close friend are having lunch in a luxury restaurant. In conversation, she says, "You've got such lovely hair. I wish mine was like that!" You say:

12. How would you respond to your male friend in the following situation? After a summer filled with barbecues and dinner parties, you have gotten a bit out of shape. You have started going back to the gym and are starting to see some great results. As you approach your friends at school one day, one of your male friends says," Wow, you look good. Have you been working out?"

13. How would you respond to your fiancée in the following situation? You are walking down the street with your fiancée. On the way, you meet a friend you haven't seen for years. You and your old friend start talking about the adventures you once had, and your fiancée asks if she can check out the store across the street. As she leaves, your friend exclaims: "I really like your fiancée. She looks nice."

14. You are an active girl. You pay attention to your foods a lot and do some activities that burn lots of calories .Your mother says to her brother "when she was very young, I offer her a healthy snack between meals if I think she is hungry". By This way she doesn't eat much at one meal and she doesn't have to wait long to eat again. From first I teach her to care about her health. Your uncle says that it's interesting that you had routines program for your eating from youth it shows you are far-sighted person. How would you respond to him?

15. How would you respond to your male manager in the following situation? You work at a store and have been asked to sort the products that you sell. You wish to impress your manager and create an easy sorting system that displays the products optimally. Your manager approaches you, looking impressed as he says, "This is a nice piece of work. Well done."

16. How would you respond to crush in the following situation? You have recently gotten together with your fiance, and you are taking him/her home to meet your parents. You are really nervous before they meet, but the meeting goes well, and you have a pleasant dinner together. After dinner, you go to your room to watch a movie as your crush says, "You have such a nice family. I really like them."

17. Your friend has invited you to his house. After dinner you try to find solution for puzzle that you and your friends have been thinking about for months. Suddenly your child pays attention to your game and looks at it for minutes and thinks deeply and solves it easily. Your friend is shocked and says "wow, it's unbelievable; your child is so intelligent". You will say:

18. Your friend has invited you to a restaurant when you want to order, he understands you are vegetarian and he got surprised and compliment you a lot and talked about its advantages. How would you respond to him?

19. Your cousin has lived in Canada for years, and after 10 years you want to meet her. When you face each other, she is surprised by your physique and says "It's incredible you have got so thin". How would you respond to her?

20. How would you respond in the following situation? You have received a prize for your outstanding work and your mother says to you, "Congratulations! Well done!" 